\title{
Characteristics of Speech Rates and Utterance Lengths in Fluent and Disfluent Utterances of Adults Who Stutter
}

\author{
HeeCheong Chon', Soo Bok Lee² \\ 'Department of Speech-Language Pathology, Chosun University, Gwangju, Korea \\ ${ }^{2}$ Department of Speech-Language Therapy \& Aural Rehabilitation, Woosong University, Daejeon, Korea \\ 말더듬 성인의 유창한 발화와 비유창한 발화의 말속도 및 발화 길이 특성 \\ 전 희 정 $\cdot$ 이 수 복 ${ }^{2}$ \\ 조선대학교 언어치료학과 ${ }^{1}$, 우송대학교 언어치료청각재활학과 ${ }^{2}$
}

\begin{abstract}
Purpose: This study aimed to investigate differences of overall speaking rate, articulation rate, and utterance length (measured in mean length of utterance-morpheme, MLU-m) in three types of utterance in adults who stutter (AWS). Methods: Participants $(n=50)$ performed reading and picture description tasks, and each utterance was categorized as a "fluent utterance" (not including any disfluencies), an "abnormal disfluencies (AD) utterance" (containing AD), or a "normal disfluencies (ND) utterance" (containing ND only). For each utterance type, mean overall speaking rate, mean articulation rate, and mean MLU-m were measured; these variables were used to compare utterance types in each task. Each participant's AD rate and ND rate from Paradise Fluency Assessment-II were also measured for correlation analyses. Results: In reading, overall speaking rate was faster in ND utterance than AD utterance, but in picture description, it was faster in fluent utterance compared to either other category. Regardless of tasks, articulation rate did not differ between utterance types. In both tasks, MLU-m was significantly the shortest in the fluent utterance. During reading, ND rate was negatively correlated with MLU$m$ in the ND utterance. Conclusion: Greater utterance length might trigger normal (linguistic) and abnormal disfluencies in AWS. Both utterance type and task influence overall speaking rate, suggesting these features be considered when assessing speech fluency in AWS.
\end{abstract}

Key Words: Stuttering, Type of utterance, Overall speaking rate, Articulation rate, Mean length of utterance-morpheme.

Received: July 2, 2019 / Revised: July 14, 2019 / Accepted: July 16, 2019

Correspondence: Soo Bok Lee, Department of Speech-Language Therapy \& Aural Rehabilitation, Woosong University, 171 Dongdaejeon-ro, Dong-gu, Daejeon 34606, Korea

Tel: +82-42-630-9222 / Fax: +82-42-630-9229 / E-mail: nosamor1@gmail.com

\section{INTRODUCTION}

화자의 말 유창성(speech fluency)에 영향을 미치는 요인 중 하나인 말속도(Chon et al., 2012)는 의사소통장애 분야에서 꾸준히 연구가 이루어지고 있다. 아동의 인지 및 언어능력과 말 운동능력의 성숙이 말속도 발달에 비선형적으로 영향을 끼치 게 되며, 청소년기 이후부터는 말운동 조절능력의 발달이 완료되 어 말속도가 더 이상 증가하지 않게 된다(Sadagopan \& Smith,

(c) This is an Open Access article distributed under the terms of the Creative Commons Attribution Non-Commercial License (https://creativecommons.org/licenses/by-nc/4.0) which permits unrestricted non-commercial use, distribution, and reproduction in any medium, provided the original work is properly cited.
2008; Sturm \& Seery, 2007). 또한 말속도는 노년기가 되면서 점 진적으로 감소하는 모습을 보이는데 이는 노화가 말운동 계획 과 통제에 부정적인 영향을 미치기 때문이다(Cheon, 2008; Duchin \& Mysak, 1987). 또한 말속도는 다양한 요인의 영향 을 받게 되는데, 말산출 과제 혹은 상황에 따라 말속도는 달라 질 수 있으며(Ahn et al., 2002; Shim, 2005), 발화 길이가 길수 록 말속도가 증가하는 경향이 있다(Ko et al., 2010; Malécot et al., 1972).

유창성장애 분야에서는 말더듬과 말속도와의 관련성에 관한 연구가 심도 있게 이루어져 왔다. 연구자들은 말속도가 말더듬 과 관계 있고 말더듬의 시작과 발달, 지속 및 회복에 중요한 역 
할을 하는 것으로 간주하여(Kloth et al., 1995; Hall et al., 1999) 말더듬는 사람의 말속도 특성을 일반인과 비교하거나 (Hall et al., 1999) 말더듬 집단 내에서 다양한 변인들을 사용 하여 말속도의 특성을 분석하였다(Chon et al., 2012; de Andrade et al., 2003; Park \& Kwon, 2010; Tumanova et al., 2011). 말속도는 분석 방식에 따라 전체말속도(overall speaking rate)와 조음속도(articulation rate)로 분류할 수 있다. 전체 말속도는 쉼과 비유창성을 모두 포함하여 말속도를 측정하는 방식으로 습관화되어 있는 화자의 말의 빠르기를 나타낸다 (Ingham \& Riley, 1998). 그리고 조음속도보다 측정 방법이 쉽 기 때문에 언어치료 임상 현장에서 화자의 말 특성을 파악하기 위하여 빈번히 사용되는 방식이다. 반면 조음속도는 말산출을 위한 조음기관 움직임의 빠르기를 음향학적인 방법으로 측정 하는 방식이기 때문에 비유창성과 $250 \mathrm{~ms}$ 이상의 쉼을 모두 제 외하게 된다(Chon et al., 2012).

말더듬과 말속도 간의 관련성을 비교한 연구결과들은 비일 관된 결과를 보고하고 있다. 말더듬 유무 및 중증도와 말속도, 그중 조음속도 간의 관련성이 낮다고 보고한 연구들은 말더듬 집단과 일반인 집단 간 조음속도에 유의한 차이가 없었으며, 말 더듬 유무 및 중증도에 따른 조음속도에도 유의한 차이가 없었 다고 하였다(Chon et al., 2012; Chon \& Lee, 2016; Yaruss \& Conture, 1995). 반면 말더듬과 말속도 간의 유의한 관련성을 보고한 연구들은 말더듬 집단의 조음속도가 일반 집단보다 유 의하게 느렸으며(Hall et al., 1999) 말더듬 빈도가 높거나 중증 도가 심할수록 전체말속도와 조음속도 모두 유의하게 느렸다 고 보고하였다(de Andrade et al., 2003; Park \& Kwon, 2010; Tumanova et al., 2011).

선행 연구들의 비일관된 결과는 실험 시 사용된 과제, 말속 도 분석 방식, 말속도 분석에 사용된 발화 내의 비유창성 유무 및 범주와 같은 다양한 실험설계상의 요인들이 영향을 미친 것 으로 보인다. 과제의 경우 자발화 과제를 사용하거나(Chon et al., 2012; de Andrade et al., 2003) 독백이나 그림설명과 같은 반구조화된 과제(Chon \& Lee, 2016), 혹은 읽기 과제(Park \& Kwon, 2010)를 사용하였다. 하지만 말속도는 말산출 과제나 상 황에 따른 가변성이 존재하므로 한 가지 과제를 사용하는 것보 다는 다양한 과제를 사용하여 말속도의 특성을 파악할 필요가 있다. 또한 전체말속도와 조음속도는 측정 목적이 다르지만 모 두 말더듬는 사람의 말운동 통제 능력을 파악할 수 있다는 장 점이 있으므로 두 측정 결과를 비교할 필요도 있다. 마지막으 로 말속도 분석을 위하여 사용하게 되는 발화 내 비유창성 유 무 및 범주는 말더듬는 사람의 말특성을 보다 면밀히 살필 수 있는 하나의 요인이 될 수 있다. 비유창성은 비정상적 비유창성 (abnormal disfluencies, AD)과 정상적 비유창성(normal dis- fluencies, ND)의 두 범주로 나눌 수 있다. $\mathrm{AD}$ 는 말더듬는 사 람에게서 주로 관찰되는 범주로 말산출 시 말운동통제의 불협 응 혹은 실패가 외현적으로 나타난 것이다(Chon et al., 2012). $\mathrm{ND}$ 는 말더듬는 사람과 말을 더듬지 않는 사람 모두에게서 관 찰되는 범주로 언어 계획 및 처리 과정에서 발생하는 문제가 구 어에 반영된 것이다(Manning \& Shirkey, 1981; Navarro-Ruiz \& Rallo-Fabra, 2001). 따라서 ND는 언어적 비유창성이라고 불리기도 하며(Manning, 2010) 말더듬 집단과 비말더듬 집단 간 ND 빈도에 유의한 차이가 없는 것으로 나타났다(Staróbole Juste \& Furquim de Andrade, 2011; Yairi \& Ambrose, 2005). 선행문헌은 말더듬는 사람들이 구문적으로 복잡하고 긴 발화 를 산출할 때 $\mathrm{AD}$ 가 발생할 가능성이 높다고 하였다(Buhr \& Zebrowski, 2009; Lee \& Sim, 2015; Logan \& Conture, 1995). 아동을 주 대상으로 하여 연구가 진행된 ND 역시 길이가 길고 복잡한 발화에서 발생 빈도가 높다고 하였다(McLaughlin \& Cullinan, 1989; Rispoli \& Hadley, 2001). 이 두 비유창성 범주 모두 말더듬는 사람에게서 관찰되며 언어적인 측면의 영향을 받지만 $\mathrm{AD}$ 가 포함된 발화와 $\mathrm{ND}$ 가 포함된 발화의 특성을 직접 적으로 비교한 연구는 매우 제한적이다. 학령 전 말더듬 아동을 대상으로 비유창성 범주에 따라 발화 유형을 분류하고 그 특 성을 살폈던 연구가 있기는 하지만(Chon et al., 2012) 이 연구 는 자발화 상황에서의 조음속도만을 비교하였으며, 발화 길이 역시 언어적인 측면이 반영된 대상자의 발화 길이를 측정한 것 이 아니라 조음속도와 언어학적인 단위를 일치시킨 음절의 수 를 사용하였다는 제한점이 있다.

따라서 본 연구는 말더듬 성인을 대상으로 하여 다양한 상 황(읽기, 그림설명)에서 유창한 발화를 산출하였을 때, ND가 포함된 발화를 산출하였을 때, 그리고 $\mathrm{AD}$ 가 포함된 발화를 산 출하였을 때 발화의 말 유창성 특성을 전체말속도와 조음속도 를 사용하여 비교하고, 구문적인 측면에서의 발화 길이인 평균 형태소길이를 비교하여 각 발화 유형의 특성을 통합적으로 파 악하고자 하였다. 또한 비유창성 범주에 따라 구별한 발화 유 형 내에서 전체말속도, 조음속도, 평균형태소길이, 그리고 비유 창성 비율 간의 관련성을 살펴보았다. 연구문제는 다음과 같다:

1) 각 과제에서 발화 유형(유창한 발화, $\mathrm{ND}$ 발화, $\mathrm{AD}$ 발화) 간 전체말속도와 조음속도에 차이가 있는가?

2) 각 과제에서 발화 유형 간 평균형태소길이에 유의한 차이 가 있는가?

3) 비유창한 발화 유형(ND발화, $\mathrm{AD}$ 발화) 내에서 전체말속 도, 조음속도, 평균형태소길이와 비유창성 비율 $(\mathrm{ND}$ 비율, $\mathrm{AD}$ 비율)의 관련성은 어떠한가? 


\section{MATERIALS AND METHODS}

\section{연구 대상}

본 연구의 참여자는 말더듬 성인 50 명(남성 43 명, 여성 7명)으 로 평균 연령은 28.17세 $( \pm$ 8.36)였다. 연구 참여자는 1) 만 18세 이상의 성인이며, 2) 한국어를 모국어로 사용하고 있고, 3) 스스 로가 자신의 말더듬 문제를 인식하고 있으며, 4) 자발화 분석 결과 100음절당 3회 이상의 말더듬 행동이 관찰되었고(Yairi \& Ambrose, 2005), 5) 언어재활사가 파라다이스-유창성검사-II (Paradise Fluency Assessment-II, P-FA-II) (Sim et al., 2010) 의 필수과제를 실시한 결과 말더듬 중증도가 ‘약함' 이상으로 진단되었고, 6) 말더듬 외 조음, 언어, 읽기, 시각, 청각 및 신경 학적인 문제를 가지고 있지 않는 경우 대상자로 선정하였다. PFA-II 평가 결과, 8명은 '약함', 24명은 '중간', 18명은 '심함' 중증 도의 말더듬으로 진단되었다(Table 1).

\section{말자료(Speech samples) 수집}

연구 참여자 선정 및 말자료 수집을 위하여 검사자는 소음 이 없는 조용한 공간에서 각 연구 참여자와 일대일로 검사를 실시하였다. 모든 연구 참여자는 P-FA-II의 필수과제를 사용 하여 말더듬 평가를 받았으며, 평가의 전 과정은 말더듬 진단, 말자료 수집 및 분석의 정확성을 위해 디지털캠코더를 사용하 여 녹화하였다. 말더듬 진단 및 중증도를 판단하기 위하여 필 수과제 분석을 통해 계산한 $\mathrm{ND}$ 비율과 $\mathrm{AD}$ 비율은 비유창한 발 화 유형 내에서의 상관분석 시 변수로 각각 사용하였다.

P-FA-II의 필수과제 중 '읽기' 과제와 '그림설명(말하기그림)' 과제 수행 시의 말자료가 말속도와 발화 길이 분석을 위하여 사 용되었다. 읽기 과제의 경우, 모든 연구 참여자에게 각 400음절로 구성된 두 개의 읽기 문단(총 800 음절)을 순서에 상관없이 모두 읽도록 하였다. 그림설명 과제는 연구 참여자가 일상생활과 관련 된 두 개의 그림을 보고 그림의 내용을 자발적으로 설명하게 하 여 수집하였으며, 평균 429.14음절( \pm 127.10$)$ 을 수집하였다.

\section{자료 분석}

비유창성 분석 및 발화 유형 분류

연구 참여자의 읽기와 그림설명 과제의 말자료를 모두 전사한
후 P-FA-II의 비유창성 분석 지침(Sim et al., 2010)을 따라 비 유창성 분석을 실시하였다. 즉, 비유창성을 모든 사람의 말에서 관찰되는 $\mathrm{ND}$ 와 말더듬는 사람에게서 주로 관찰되는 $\mathrm{AD}$ 로 분 류하였다. ND에는 주저, 간투사, 미완성/수정, 반복 1이 포함되 었으며, $\mathrm{AD}$ 에는 주저-비정상적, 간투사-비정상적, 미완성/수 정-비정상적, 반복 1-비정상적, 반복 2, 비운율적 발성(연장, 막 힘, 깨진 낱말)이 포함되었다. 각 연구 참여자의 말자료에서 비 유창성이 관찰된 경우, 비유창성 유형을 말자료에 직접 코딩하 였다. 읽기 과제에서의 $\mathrm{ND}$ 비율은 평균 $0.69 \%( \pm 0.71), \mathrm{AD}$ 비 율은 평균 $1.93 \%( \pm 2.34)$ 였으며, 그림설명 과제에서의 $\mathrm{ND}$ 비 율은 평균 4.69\%( \pm 2.79$), \mathrm{AD}$ 비율은 평균 $3.56 \%( \pm 2.88)$ 였다.

비유창성 분석을 마친 후 말자료를 Chon et al.(2013)의 발화 구분 기준에 따라 발화로 나누었다. 각 참여자의 말자료에서 분 석된 읽기 과제의 발화 수는 평균 33.00개( \pm 1.00$)$ 였으며, 그림 설명 과제의 발화 수는 평균 16.56 개 $( \pm 5.20)$ 였다. 과제별로 각 발화는 비유창성 유무 및 범주에 따라 세 개의 유형으로 분류 하였다. 즉, 발화에 비유창성이 관찰되지 않은 경우 '유창한 발 화, 발화 내에서 $\mathrm{ND}$ 가 관찰된 경우 ' $\mathrm{ND}$ 발화', 발화 내에서 $\mathrm{AD}$ 가 관찰된 경우 ' $\mathrm{AD}$ 발화로 분류하였다. 발화 내에 $\mathrm{ND}$ 와 $\mathrm{AD}$ 가 모두 관찰된 경우 'AD발화로 분류하였다(Chon \& Lee, 2016).

본 연구의 종속변수인 전체말속도와 조음속도, 평균형태소 길이는 과제와 발화 유형별로 평균값을 계산하여 측정하였다. 이는 각 연구 참여자의 말자료에서 수집한 발화의 개수가 과제 및 발화 유형에 따라 서로 달랐기 때문이기도 하지만 발화 유 형에 따른 말속도와 발화 길이의 대표성을 확보하기 위해서였 다(Chon et al., 2012; Chon \& Lee, 2016). 따라서 각 과제(읽 기, 그림설명)와 발화 유형(유창한 발화, $\mathrm{ND}$ 발화, $\mathrm{AD}$ 발화)에 포함된 발화가 없었거나 1 개였던 경우 분석에서 제외하였다. 읽 기 과제에서 사용된 유창한 발화의 수는 평균 21.33개( \pm 7.80$)$, $\mathrm{ND}$ 발화의 수는 평균 4.06개 $( \pm 2.02), \mathrm{AD}$ 발화의 수는 평균 10.26 개 $( \pm$ 8.66)였다. 그림설명 과제에서 사용된 유창한 발화 수는 평균 5.17개( \pm 2.62), ND발화 수는 평균 6.11개( \pm 3.12$)$, $\mathrm{AD}$ 발화 수는 평균 8.47 개 $( \pm 5.38)$ 였다.

\section{전체말속도 및 조음속도 분석}

말속도를 분석하기 위해 디지털 영상으로 수집된 각 참여자 의 말자료를 Goldwave 5.7 (Goldwave Inc., St. John's, Canada)

Table 1. Participants' information

\begin{tabular}{lrcccc}
\hline \multirow{2}{*}{ Sex } & \multirow{n}{*}{$\mathrm{n}$} & Mean age $( \pm$ SD $)$ & Mean ND rate $( \pm$ SD $)$ & Mean AD rate $( \pm$ SD $)$ & Stuttering severity \\
\cline { 4 - 6 } & & & $10.02( \pm 4.86)$ & $9.17( \pm 8.04)$ & 5 mild, 21 moderate, 17 severe \\
Male & 43 & $27.42( \pm 7.91)$ & $9.86( \pm 8.41)$ & $6.69( \pm 7.80)$ & 3 mild, 3 moderate, 1 severe \\
Female & 7 & $32.86( \pm 10.29)$ & $10.00( \pm 5.24)$ & $8.83( \pm 7.97)$ & 8 mild, 24 moderate, 18 severe \\
Total & 50 & $28.17( \pm 8.36)$ &
\end{tabular}

SD: standard deviation, P-FA-II: Paradise Fluency Assessment-II, ND: normal disfluencies, AD: abnormal disfluencies 
(Craig, 2013)을 사용하여 오디오 파일(wav file format)로 변환 하는 절차를 거쳤다. 변환 시 sampling rate는 $44 \mathrm{kHz}$ 로 설정 하였다. 그 후 Praat 5.4.18 (Boersma \& Weenink, 2015)을 사 용하여 각 대상자로부터 발화를 캡처한 후 과제별로 그리고 발 화 유형별로 분류하여 저장하였다. 말속도 분석의 기준은 선행 연구를 따라 초당음절수(syllables per second, SPS)로 계산하 였다(Chon \& Lee, 2016; Ingham \& Riley, 1998). 앞서 설명하 였듯이 말속도를 측정하기 위해 각 발화의 말속도를 분석한 후 과제별, 발화 유형별로 평균 말속도를 계산하였다. 즉, 각 연구 참여자로부터 읽기 과제와 그림설명 과제에서 유창한 발화의 평균 말속도, $\mathrm{ND}$ 발화의 평균 말속도, $\mathrm{AD}$ 발화의 평균 말속도 를 각각 계산하였다.

\section{전체말속도 분석}

전체말속도는 발화에서 의미전달음절수, 즉, 화자가 의도하 여 산출한 언어학적인 의미를 가지고 있는 음절의 수를 센 후 이를 발화를 산출하는 데 걸린 시간(초)으로 나누어 초당음절 수로 측정하였다(Hall et al., 1999). 이때 2초 이상의 비정상적 인 쉼의 지속시간은 제외하였다(Hall et al., 1999). 발화산출에 걸린 시간과 비정상적인 쉼의 지속시간을 측정하기 위하여 Praat 5.4.18 (Boersma \& Weenink, 2015)을 사용하였다. ND 발화와 $\mathrm{AD}$ 발화의 경우 의미전달음절수를 계산하기 위하여 전 사된 발화의 전체 음절수에서 간투사나 반복 시 관찰되는 반 복단위(repetition units)처럼 의미 전달과 관련 없는 비유창한 음절수를 제외하였다.

\section{전체말속도 $(\mathrm{SPS})=$}

\section{의미전달음절수}

발화산출에 걸린 시간 - 비정상적인 쉼의 지속시간

조음속도 분석

조음속도는 발화 내에서 유창하게 산출한 음절의 수를 센 후 이를 유창하게 산출한 음절의 지속시간(초)으로 나누어 초 당음절수를 측정하였으며, 발화 내에 $250 \mathrm{~ms}$ 이상의 쉼이 발생 한 경우 지속시간에서 제외하였다(Andrews et al., 1982; Chon et al., 2013; Chon \& Lee, 2016; Hall et al., 1999; Miller et al., 1984). $\mathrm{ND}$ 발화와 $\mathrm{AD}$ 발화의 경우 발화 내에 비유창하게 산출된 음절을 제외하고 유창한 음절의 수를 계산하였다. 조음 속도 역시 Praat 5.4.18 (Boersma \& Weenink, 2015)을 사용하 여 지속시간을 측정하였다. 유창한 발화는 발화를 산출하는 데 걸린 전체 지속시간을 측정한 후 $250 \mathrm{~ms}$ 이상 쉼의 지속시간을 측정하여 전체 지속시간에서 제외하였다. $\mathrm{ND}$ 발화와 $\mathrm{AD}$ 발화 의 경우 발화를 산출하는 데 걸린 전체 지속시간을 측정한 후
$250 \mathrm{~ms}$ 이상 쉼의 지속시간과 비유창성의 지속시간을 각각 측 정하여 전체 지속시간에서 제외하였다.

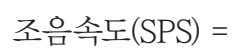

발화산출에 걸린 시간 $-250 \mathrm{~ms}$ 이상 심의 지속시간-비유창성의 지속시간

\section{발화 길이(평균형태소길이, $M L U-m)$ 분석}

평균형태소길이(mean length of utterance-morpheme, MLU-m)는 P-FA-II의 기준에 따라 발화에서 비유창하게 산 출된 음절을 제외하고 형태소 분석을 실시하였다. 형태소의 정 의는 $\operatorname{Kim}(1997)$ 을 참고하였다. 과제와 발화 유형별로 모든 형 태소(실질형태소와 형식형태소)를 구하고 총 발화의 수로 나누 어 MLU-m을 각각 측정하였다.

$$
\text { 평균형태소길이 }=\frac{\text { 실질형태소 }+ \text { 형식형태소 }}{\text { 총 발화 수 }}
$$

\section{신뢰도 측정}

신뢰도 측정을 위하여 전체 자료의 $16 \%$ 인 8 명의 자료를 무 작위로 선정하였다. 본 연구에서 변수로 사용된 발화 유형(유 창한 발화, $\mathrm{ND}$ 발화, $\mathrm{AD}$ 발화), 전체말속도, 조음속도 및 $\mathrm{P}-\mathrm{FA}-$ $\mathrm{II}$ 필수과제의 $\mathrm{ND}$ 비율과 $\mathrm{AD}$ 비율에 대한 평가자 간 신뢰도는 제1저자와 제 1 저자에게 비유창성 분석과 말속도 분석에 대한 훈련을 받은 평가자에 의해 독립적으로 이루어졌다. 이 평가자 는 언어재활사 2급 국가자격증을 소지하고 있으며 언어치료학 과 대학원 석사 과정에서 유창성장애를 전공하고 있었다. 또 다른 변수였던 MLU-m의 평가자 간 신뢰도는 제 2 저자와 언어 치료학과 학부 과정에 재학 중이며 제2저자로부터 MLU-m 측 정에 대한 훈련을 받은 평가자에 의해 독립적으로 이루어졌다. 발화 유형과 MLU-m은 일치율(\%) 분석을 통하여 신뢰도를 측 정하였으며, 전체말속도와 조음속도, $\mathrm{ND}$ 비율과 $\mathrm{AD}$ 비율은 Pearson 적률상관계수를 구하여 신뢰도를 측정하였다.

발화 유형을 분류하는 평가자 간 일치율은 읽기 과제와 그림 설명 과제 모두 $100 \%$ 로 나타났다. MLU-m은 발화에서 일치한 형태소의 수를 발화에 나타난 형태소의 총 수로 나눈 후 100을 곱하여 평가자 간 신뢰도를 측정하였다. 그 결과 읽기 과제에서 $89.06 \%$, 그림설명 과제에서 $85.5 \%$ 의 일치율을 보였다.

전체말속도는 읽기 과제에서 유창한 발화의 상관계수가 0.997, ND발화 0.997, $\mathrm{AD}$ 발화 0.984로 나타났으며, 그림설명 과 제에서 유창한 발화의 상관계수가 0.993, ND발화 0.989, $\mathrm{AD}$ 발 화 0.980 으로 높게 나타났다. 조음속도는 읽기 과제에서 유창한 발화의 상관계수 $0.942, \mathrm{ND}$ 발화 0.993, $\mathrm{AD}$ 발화 0.981로 나타 
났으며, 그림설명 과제에서 유창한 발화의 상관계수 $0.987, \mathrm{ND}$ 발화 0.990, AD발화 0.985로 나타났다. P-FA-II의 ND비율에 대한 평가자 간 신뢰도는 $0.985, \mathrm{AD}$ 비율에 대한 평가자 간 신 뢰도는 0.925 로 나타났다.

\section{통계 분석}

자료의 통계 분석을 위하여 IBM SPSS Statistics 24 (IBM Corp., Armonk, NY, USA)를 사용하였다. 본 연구에서 전체 말속도와 조음속도 측정을 위해 분석한 음절의 평균 길이(음절 수)가 말속도에 영향을 미치는 가외변수가 될 수 있는지 확인하 기 위하여 각 과제와 발화 유형별로 전체말속도와 '내용전달음 절수’ 간, 그리고 조음속도와 ‘유창한 음절수’ 간의 상관분석을 실시하였다. 이는 선행연구를 따라 잠재적인 가외변수를 말속도 측정 시 사용한 언어학적 단위(음절)와 일치시키기 위함이었다 (Chon \& Lee, 2016). Pearson 적률상관분석 결과 각 과제와 발화 유형별 전체말속도와 내용전달음절수 사이에는 유의한 상 관이 없는 것으로 나타났다. 조음속도와 유창한 음절수 간에도 유의한 상관이 나타나지 않았다.

발화 유형에 따른 전체말속도, 조음속도, MLU-m을 각각 비 교하기 위하여 대응표본 $t$-검정을 실시하였으며, 과제별로 '유창 한 발화-ND발화, '유창한 발화-AD발화, 'AD발화-ND발화' 간의 비교가 연속해서 이루어졌기 때문에 제1종 오류의 가능 성을 감소시키기 위하여 Bonferroni 교정을 실시하였다(전체 alpha level $=0.05$, 각각의 비교를 위한 수정된 alpha level = $0.05 / 6$ = 0.008). 읽기 과제에서 '유창한 발화-ND발화' 간 비교 는 31 명의 자료가 사용 가능하였으며, '유창한 발화-AD발화' 간 비교는 45명, 'AD발화-ND발화'는 29명의 자료를 사용할 수 있 었다. 그림설명 과제에서 '유창한 발화-ND발화' 간 비교는 29명 의 자료가 사용 가능하였으며, '유창한 발화-AD발화' 간 비교 는 32명, 'AD발화-ND발화는 35명의 자료를 사용할 수 있었다.

각 비유창한 발화 유형( $\mathrm{ND}$ 발화, $\mathrm{AD}$ 발화) 내에서 전체말속 도, 조음속도, MLU-m과 비유창성 비율(ND비율, $\mathrm{AD}$ 비율)의 관련성을 확인하기 위하여 Pearson 적률상관분석을 각각 실시 하였다.

\section{RESULTS}

\section{전체말속도 비교}

대응표본 $t$-검정을 사용하여 읽기 과제에서 발화 유형 간 전 체말속도를 비교한 결과는 Table 2에 제시하였다. 유창한 발화 는 다른 발화 유형과 유의한 차이를 보이지 않았으나, $\mathrm{AD}$ 발화 는 ND발화보다 전체말속도가 유의하게 느린 것으로 나타났다 $(t=-3.179, p<0.008)$. 그림설명 과제에서 발화 유형 간 전체말
속도를 비교한 결과, 유창한 발화가 ND발화 $(t=7.467, p<$ $0.001)$ 와 $\mathrm{AD}$ 발화 $(t=9.252, p<0.001)$ 보다 전체말속도가 유 의하게 빠른 것으로 나타났다. $\mathrm{AD}$ 발화와 $\mathrm{ND}$ 발화 간에는 전체

Table 2. The results of the paired $t$-test with Bonferroni correction for overall speaking rate (measured in syllables per second)

\begin{tabular}{cccccc}
\hline Tasks & Utterance pairs & Mean \pm SD & $\mathrm{n}$ & $t$ & $p$-value \\
\hline Reading & \multicolumn{1}{c}{ Fluent-ND utterance pair } & & & \\
& Fluent & $5.79 \pm 1.06$ & & & \\
& ND & $5.96 \pm 5.32$ & 31 & -0.190 & 0.850 \\
& Fluent-AD utterance pair & & & \\
& Fluent & $5.80 \pm 0.97$ & & & \\
& AD & $5.21 \pm 3.76$ & 45 & 1.135 & 0.262 \\
& AD-ND utterance pair & & & \\
Picture & AD & $5.41 \pm 4.67$ & & & \\
description & ND & $6.05 \pm 5.50$ & 29 & -3.179 & $0.004^{*}$ \\
& Fluent & $5.12 \pm 1.18$ & & & \\
& ND & $3.99 \pm 0.88$ & 29 & 7.467 & $0.000^{\dagger}$ \\
& Fluent-AD utterance pair & & & \\
& Fluent & $5.19 \pm 1.19$ & & & \\
& AD & $3.69 \pm 0.92$ & 32 & 9.252 & $0.000^{\dagger}$ \\
& AD-ND utterance pair & & & \\
& AD & $3.69 \pm 0.96$ & & & \\
& ND & $3.88 \pm 0.84$ & 35 & -1.847 & 0.073 \\
\hline
\end{tabular}

${ }^{*} p<0.008,{ }^{\dagger} p<0.001$ (corrected alpha level per comparison $=$ 0.008 , overall alpha $=0.05)$. SD: standard deviation, ND: normal disfluencies, AD: abnormal disfluencies

Table 3. The results of the paired $t$-test with Bonferroni correction for articulation rate (measured in syllables per second)

\begin{tabular}{|c|c|c|c|c|c|}
\hline Tasks & Utterance pairs & Mean \pm SD & $\mathrm{n}$ & $t$ & $\overline{p \text {-value }}$ \\
\hline \multirow[t]{9}{*}{ Reading } & \multicolumn{5}{|c|}{ Fluent-ND utterance pair } \\
\hline & Fluent & $6.09 \pm 1.00$ & \multirow{2}{*}{31} & \multirow{2}{*}{-0.846} & \multirow{2}{*}{0.404} \\
\hline & ND & $6.82 \pm 5.17$ & & & \\
\hline & \multicolumn{5}{|c|}{ Fluent-AD utterance pair } \\
\hline & Fluent & $6.10 \pm 0.88$ & \multirow{2}{*}{45} & \multirow{2}{*}{-0.542} & \multirow{2}{*}{0.591} \\
\hline & $\mathrm{AD}$ & $6.36 \pm 3.57$ & & & \\
\hline & \multicolumn{5}{|c|}{ AD-ND utterance pair } \\
\hline & $\mathrm{AD}$ & $6.55 \pm 4.43$ & \multirow{2}{*}{29} & \multirow{2}{*}{-1.830} & \multirow{2}{*}{0.078} \\
\hline & ND & $6.90 \pm 5.34$ & & & \\
\hline \multirow{9}{*}{$\begin{array}{l}\text { Picture } \\
\text { description }\end{array}$} & \multicolumn{5}{|c|}{ Fluent-ND utterance pair } \\
\hline & Fluent & $6.04 \pm 1.12$ & \multirow{2}{*}{29} & \multirow{2}{*}{0.406} & \multirow{2}{*}{0.688} \\
\hline & ND & $5.99 \pm 0.99$ & & & \\
\hline & \multicolumn{5}{|c|}{ Fluent-AD utterance pair } \\
\hline & Fluent & $6.08 \pm 1.11$ & \multirow{2}{*}{32} & \multirow{2}{*}{2.148} & \multirow{2}{*}{0.040} \\
\hline & $\mathrm{AD}$ & $5.85 \pm 1.07$ & & & \\
\hline & \multicolumn{5}{|c|}{ AD-ND utterance pair } \\
\hline & $\mathrm{AD}$ & $5.93 \pm 1.04$ & \multirow{2}{*}{35} & \multirow{2}{*}{-0.251} & \multirow{2}{*}{0.803} \\
\hline & ND & $5.95 \pm 0.99$ & & & \\
\hline
\end{tabular}

$\overline{p<0.008 \text { (corrected alpha level per comparison }=0.008 \text {, overall al- }}$ pha $=0.05)$. SD: standard deviation, ND: normal disfluencies, $\mathrm{AD}$ : abnormal disfluencies 
말속도에 유의한 차이가 없었다(Table 2).

\section{조음속도 비교}

대응표본 $t$-검정 결과, 읽기 과제와 그림설명 과제 모두 발화 유형에 따른 조음속도에 유의한 차이가 없는 것으로 나타났다 (Table 3).

\section{발화 길이(평균형태소길이) 비교}

읽기 과제에서 발화 유형 간 대응표본 $t$-검정 결과, $\mathrm{ND}$ 발화 가 유창한 발화보다 MLU-m이 유의하게 길었으며 $(t=-4.571, p$ < 0.001), $\mathrm{AD}$ 발화 역시 유창한 발화보다 MLU-m이 유의하게 긴 것으로 나타났다 $(t=-6.243, p<0.001)$. 그림설명 과제도 읽기 과제와 동일하게 ND발화가 유창한 발화보다 MLU-m이 유의하게 길었으며 $(t=-5.197, p<0.001), \mathrm{AD}$ 발화 역시 유창한 발화보다 MLU-m이 유의하게 긴 것으로 나타났다 $(t=-5.747$, $p<0.001$ ) (Table 4).

\section{전체말속도, 조음속도, 평균형태소길이와 비유창성 비율 간 상관}

\section{$\mathrm{ND}$ 발화}

$\mathrm{ND}$ 발화의 전체말속도, 조음속도, MLU-m과 P-FA-II의 필 수과제에서 분석된 연구 참여자의 $\mathrm{ND}$ 비율 간 상관을 분석한 결과, 읽기 과제에서 MLU-m과 ND비율 간 유의한 부적 상관이

Table 4. The results of the paired $t$-test with Bonferroni correction for mean length of utterance-morpheme

\begin{tabular}{cccccc}
\hline Tasks & Utterance pairs & Mean \pm SD & $\mathrm{n}$ & $t$ & p-value \\
\hline Reading & Fluent-ND utterance pair & & & \\
& Fluent & $16.84 \pm 1.24$ & & & \\
& ND & $25.41 \pm 10.41$ & 31 & -4.571 & $0.000^{*}$
\end{tabular}

Fluent-AD utterance pair

$\begin{array}{lllll}\text { Fluent } & 16.30 \pm 1.90 & & & \\ \mathrm{AD} & 20.43 \pm 3.90 & 45 & -6.243 & 0.000^{*}\end{array}$

AD-ND utterance pair

$$
\begin{array}{lllll}
\mathrm{AD} & 19.63 \pm 4.21 & 29 & -2.304 & 0.029 \\
\mathrm{ND} & 24.94 \pm 10.60 & & &
\end{array}
$$

Picture Fluent-ND utterance pair

$\begin{array}{ccrrrr}\text { description } & \text { Fluent } & 15.31 \pm 4.91 & & & \\ & \text { ND } & 19.98 \pm 6.57 & 29 & -5.197 & 0.000^{*} \\ & \text { Fluent-AD utterance pair } & & & \\ \text { Fluent } & 14.99 \pm 4.44 & & & \\ \text { AD } & 20.75 \pm 6.06 & 32 & -5.747 & 0.000^{*} \\ \text { AD-ND utterance pair } & & & \\ \text { AD } & 21.22 \pm 5.90 & & & \\ \text { ND } & 19.57 \pm 6.12 & 35 & 1.477 & 0.149\end{array}$

${ }^{*} p<0.001$ (corrected alpha level per comparison $=0.008$, overall alpha $=0.05)$. SD: standard deviation, ND: normal disfluencies, AD: abnormal disfluencies
있는 것으로 나타났다 $(\mathrm{r}=-0.369, p<0.05)$. 과제와 상관없이 전체말속도와 조음속도 간에는 유의한 정적 상관을 보였다(읽 기: $\mathrm{r}=0.997, p<0.001$; 그림설명: $\mathrm{r}=0.800, p<0.001)(\mathrm{Ta}-$ ble 5).

$A D$ 발화

$\mathrm{AD}$ 발화의 전체말속도, 조음속도, MLU-m과 P-FA-II의 필 수과제에서 분석된 연구 참여자의 $\mathrm{AD}$ 비율 간 상관을 분석한 결과, 읽기 과제에서 전체말속도와 MLU-m 간 유의한 정적 상 관이 있었으며 $(\mathrm{r}=0.421, p<0.05)$, 조음속도와 MLU-m 간에 도 유의한 정적 상관이 나타났다 $(\mathrm{r}=0.397, p<0.05) . \mathrm{AD}$ 발화 역시 과제와 상관없이 전체말속도와 조음속도 간에는 유의한 정적 상관을 보였다(읽기: $\mathrm{r}=0.989, p<0.001$; 그림설명: $\mathrm{r}=$ $0.735, p<0.001$ ) (Table 6).

\section{DISCUSSIONS}

본 연구는 말더듬 성인의 발화에서 관찰된 비유창성 유무

Table 5. The results of correlations among overall speaking rate, articulation rate, MLU-m, and ND rate (P-FA-II) of ND utterance in

\begin{tabular}{|c|c|c|c|}
\hline & $\begin{array}{c}\text { Articulation } \\
\text { rate }\end{array}$ & MLU-m & ND rate \\
\hline \multicolumn{4}{|l|}{ Reading $(\mathrm{n}=31)$} \\
\hline Overall speaking rate & $0.997^{\dagger}$ & 0.108 & -0.174 \\
\hline Articulation rate & & 0.093 & -0.158 \\
\hline MLU-m & & & $-0.369^{*}$ \\
\hline \multicolumn{4}{|l|}{ Picture description $(\mathrm{n}=38)$} \\
\hline Overall speaking rate & $0.800^{\dagger}$ & 0.150 & -0.114 \\
\hline Articulation rate & & 0.197 & -0.034 \\
\hline MLU-m & & & -0.071 \\
\hline
\end{tabular}
each task

Table 6. The results of correlations among overall speaking rate, articulation rate, MLU-m, and AD rate (P-FA-II) of AD utterance in each task

\begin{tabular}{lccc}
\hline & $\begin{array}{c}\text { Articulation } \\
\text { rate }\end{array}$ & MLU-m & AD rate \\
\hline Reading $(\mathrm{n}=46)$ & & & \\
$\quad$ Overall speaking rate & $0.989^{\dagger}$ & $0.421^{*}$ & -0.118 \\
$\quad$ Articulation rate & & $0.397^{*}$ & -0.044 \\
$\quad$ MLU-m & & & -0.171 \\
Picture description ( $\mathrm{n}=47)$ & & & \\
$\quad$ Overall speaking rate & $0.735^{\dagger}$ & 0.022 & -0.233 \\
$\quad$ Articulation rate & & -0.133 & -0.040 \\
MLU-m & & & -0.052 \\
\hline
\end{tabular}

${ }^{*} p<0.05,{ }^{\dagger} p<0.001$. MLU-m: mean length of utterance-morpheme, AD: abnormal disfluencies, P-FA-II: Paradise Fluency Assessment-II 
및 범주에 따라 발화를 세 가지 유형으로 나누고, 발화 유형에 따른 말속도와 발화 길이의 특성을 살펴보았다. 두 개의 과제 를 사용하여 과제에 따른 특성을 각각 확인해보고자 하였으며, 말속도와 발화 길이가 말더듬 성인의 비유창성 비율과 관련성 이 있는지를 살펴보았다.

\section{전체말속도 및 조음속도}

그림설명 과제와 읽기 과제에서 발화 유형에 따른 전체말속 도 비교 결과는 상반되게 나타났다.

그림설명 과제에서 유창한 발화는 $\mathrm{AD}$ 발화와 $\mathrm{ND}$ 발화보다 유의하게 빠른 전체말속도를 보였다. 유창한 발화와 비유창한 발화의 전체말속도를 직접적으로 비교한 선행문헌은 제한적이 지만 이러한 결과는 어느 정도 예측 가능하였다. 전체말속도는 비유창성의 지속시간과 2초 미만 쉼의 지속시간이 말속도 측정 에 포함된다. 따라서 비유창성의 범주(ND, AD)와 상관없이 비 유창한 발화는 비유창성의 양적인 측면, 즉, 발화 내에 비유창 성의 발생 빈도뿐만 아니라 질적인 측면, 예를 들어 반복 시 나 타나는 반복단위나 비운율적 발성(연장, 막힘, 깨진 낱말)의 지 속시간 등으로 인해 전체말속도가 감소되었을 것으로 예측할 수 있다. 반면, 읽기 과제에서 유창한 발화의 전체말속도는 ND 발화 및 $\mathrm{AD}$ 발화와 유의한 차이가 없었으며, $\mathrm{ND}$ 발화가 $\mathrm{AD}$ 발 화보다 전체말속도가 유의하게 빠른 것으로 나타났다. 이는 읽 기를 위해 시각적 자극인 문자가 제시되어 언어 계획 및 처리 과정에 대한 부담이 그림설명 과제와 같은 자발화 산출보다 적 었기 때문으로 추측해볼 수 있다. 우선 인지 및 언어적인 측면 을 반영하는 요인 중 하나인 쉼은(Kim et al., 2006) 읽기에서 문자 자극과 문법적인 경계가 명확하게 제시되기 때문에 그 빈 도가 감소하고 지속시간이 짧아질 수 있을 것이다(Howell \& Kadi-Hanifi, 1991). 또한 ND는 읽기 상황에서의 빈도 자체가 자발화 상황보다 감소하여(Shim, 2005) 비유창성의 지속시간 이 전체말속도에 미치는 영향이 감소했을 수 있다. 본 연구에서 도 모든 연구 참여자가 그림설명 과제보다 읽기 과제에서 상대 적으로 낮은 $\mathrm{ND}$ 비율을 보였으며, $\mathrm{ND}$ 비율 자체도 읽기 과제에 서 평균 $0.69 \%( \pm 0.71)$ 로 그림설명 과제에서의 평균 $4.69 \%( \pm$ 2.79)보다 확연히 낮게 분석되었다. 이러한 비율의 차이는 분석 에 포함된 발화 수에도 영향을 미쳤는데, 읽기 과제에서는 평균 $\mathrm{ND}$ 발화 수가 4.06개( \pm 2.02)로 그림설명 과제에서의 평균 ND 발화 수 6.11개( \pm 3.12)보다 낮게 나타났다. 반면 문자 자극으 로 인해 언어적인 측면의 부담이 줄어들었다 하더라도 $\mathrm{AD}$ 는 말산출을 위한 말운동통제의 불협응으로 인해 발생한 비유창 성이다. 따라서 조음기관의 움직임이 다시 협응을 이루어 유창 한 말을 산출하기까지 $\mathrm{AD}$ 의 지속시간은 전체말속도에 영향을 미쳤을 것이다. 또한 읽기 과제의 특성상 말더듬 성인이 특정
단어나 음절에서 말더듬이 예상되더라도 이를 회피할 수 없기 때문에(Manning, 2010) $\mathrm{AD}$ 의 빈도가 $\mathrm{ND}$ 처럼 읽기에서 일관 되게 감소하지 않고 연구 참여자에 따라 다양하게 나타났을 수 있다. 실제 본 연구의 참여자 50명 중 8명(16\%)은 그림설명 과 제와 비교하였을 때 읽기 과제에서의 $\mathrm{AD}$ 비율이 동일하거나 오 히려 증가하는 모습을 보였다. 이는 $\mathrm{AD}$ 발화가 $\mathrm{ND}$ 발화보다 전 체말속도가 유의하게 느렸던 원인이 되었던 것으로 보인다. 하 지만 $\mathrm{AD}$ 발화와 $\mathrm{ND}$ 발화의 전체말속도 변동성이 커서 유창한 발화 간 전체말속도 비교 시에는 유의한 차이가 나타나지 않았 던 것으로 생각한다.

조음속도의 경우, 두 과제 모두에서 발화 유형에 따른 차이 가 나타나지 않았다. 이러한 결과는 발화 유형에 따른 말더듬 아동의 조음속도에 유의한 차이가 없었다고 보고한 선행연구 와 맥락이 같다(Chon et al., 2012; Chon \& Lee, 2016). 조음속 도의 경우 비유창한 음절의 지속시간과 $250 \mathrm{~ms}$ 이상 쉼의 지 속시간을 제외하고 측정하기 때문에 전체말속도와는 달리 비 유창성과 쉼의 영향이 배제된다. 따라서 말더듬 성인의 말운동 안정성(speech motor stability)이 낮아 $\mathrm{AD}$ 가 발생하여도 (Kleinow \& Smith, 2000) 조음속도 분석 방식을 따른다면 AD 발화의 조음속도는 유창한 발화와 차이가 나지 않을 가능성이 크다. $\mathrm{AD}$ 발생 후 말운동통제가 다시 이루어지게 된다면 발화 를 다시 유창하게 산출하게 되는데, 조음속도는 그 유창한 발화 만을 사용하여 분석하기 때문이다. 즉, 조음속도와 같이 조음기 관의 움직임의 속도를 음향학적인 방법을 통해 분석하는 방법 은 말더듬 순간의 특성을 파악하는 데는 한계가 있을 수 있다.

\section{발화 길이}

평균형태소길이(MLU-m)를 사용하여 발화 유형에 따른 발 화 길이를 비교한 결과 과제와 상관없이 $\mathrm{ND}$ 발화와 $\mathrm{AD}$ 발화의 MLU-m이 유창한 발화에 비해 긴 것으로 나타났고 $\mathrm{AD}$ 발화 와 $\mathrm{ND}$ 발화 간에는 유의미한 차이가 없는 것으로 나타났다. 이 는 $\mathrm{ND}$ 발화와 $\mathrm{AD}$ 발화가 유창한 발화보다 발화 길이가 유의하 게 길었다고 보고한 선행연구의 결과를 지지한다(Lee \& Sim, 2015; Logan \& Conture, 1995; McLaughlin \& Cullinan, 1989; Rispoli \& Hadley, 2001; Zackheim \& Conture, 2003). 하지만 선행연구들은 ND발화와 유창한 발화만을 비교하거나 $\mathrm{AD}$ 발화와 유창한 발화만을 비교하여 보고된 결과들이었다. $\mathrm{ND}$ 발화와 $\mathrm{AD}$ 발화의 발화 길이를 직접적으로 비교한 이번 결 과를 통해 말운동통제의 불협응 혹은 실패로 인해 나타나게 되는 $\mathrm{AD}$ (Chon et al., 2012)뿐만 아니라 언어 계획과 처리 과정 에서 발생하는 ND(Manning \& Shirkey, 1981; Navarro-Ruiz \& Rallo-Fabra, 2001) 모두 발화 길이의 영향을 받을 수 있으 며, 그 영향의 정도는 $\mathrm{ND}$ 와 $\mathrm{AD}$ 간에 크게 다르지 않았음을 확 
인할 수 있었다. $\mathrm{ND}$ 발화와 $\mathrm{AD}$ 발화 간 $\mathrm{MLU}-\mathrm{m}$ 은 과제와 상 관없이 유의한 차이를 보이지 않았기 때문이다. 또한 이러한 언 어적인 측면의 영향으로 인하여 길고 복잡한 발화 내에 $\mathrm{ND}$ 와 $\mathrm{AD}$ 가 동시에 혹은 함께 발생할 수 있다는 것을 추측해볼 수 있다. 예를 들어, Robb et al.(2009)은 말더듬 성인의 자발화를 분석한 결과 $\mathrm{ND}$ 와 $\mathrm{AD}$ 가 함께 나타난 복합 비유창성군의 빈 도가 $\mathrm{ND}$ 만을 포함한 비유창성군이나 $\mathrm{AD}$ 만을 포함한 비유창 성군의 빈도보다 유의하게 많았으며, 비유창성군의 발화 길이 가 유창한 발화보다 유의하게 길었다고 보고하였다.

\section{전체말속도, 조음속도, 평균형태소길이와 비유창성 비율 간 상관}

$\mathrm{ND}$ 발화와 $\mathrm{AD}$ 발화의 말속도와 발화 길이 특성이 말더듬 성 인이 산출한 비유창성 비율과 관련이 있는지 살피기 위하여 실 시한 상관분석 결과, $\mathrm{ND}$ 발화와 $\mathrm{AD}$ 발화 모두에서 전체말속도 와 조음속도 간 높은 정적 상관을 보였다. 이는 말속도 분석 방 식이 어떠하든 화자의 습관적인 말산출의 빠르기는 비슷한 양 상을 보인다고 할 수 있을 것이다. 또한 읽기 과제에서 $\mathrm{AD}$ 발화 의 MLU-m은 전체말속도 및 조음속도와 유의한 정적 상관을 보였다. 이는 ND발화의 경우 읽기 과제의 전체말속도 및 조음 속도와 MLU-m 간에 상관이 없었던 것과 대조적이다. 상관의 정도가 높지 않았지만 이번 결과는 읽기 상황에서 긴 발화의 조음속도가 짧은 발화보다 유의하게 빨랐음을 보고한 Ko et al.(2010)의 연구와 어느 정도 맥락을 같이한다고 할 수 있다. 긴 발화를 읽을 때 화자 스스로 자신의 호흡 단위 내에서 발화 산출을 하기 위하여 말운동을 빠르게 조절하기 때문으로 보이 며, 이러한 과정에서 말산출을 위한 협응이 적절히 이루어지지 않아 $\mathrm{AD}$ 가 나타났을 것으로 유추해볼 수 있을 것이다. 또한 과제와 상관없이 $\mathrm{AD}$ 발화의 전체말속도 및 조음속도와 $\mathrm{AD}$ 비 율 간에는 유의한 상관이 나타나지 않았다. 이는 말더듬 중증 도에 따른 전체말속도와 조음속도에 유의한 차이가 있었다고 보고한 선행연구(de Andrade et al., 2003; Park \& Kwon, 2010) 와 반대되는 결과이다. 이러한 결과는 본 연구의 실험설계상의 차이로 해석할 수 있다. 본 연구의 결과는 $\mathrm{AD}$ 가 포함된 발화 만을 사용하여 $\mathrm{AD}$ 비율과의 상관을 살펴본 것인 반면 선행연 구들은 발화의 유형을 고려하지 않고 통합하여 결과를 얻었기 때문이다. 마지막으로 ND발화는 읽기 과제에서 MLU-m이 증 가하면 $\mathrm{ND}$ 비율이 감소하는 부적 상관을 보였다. $\mathrm{ND}$ 의 특성 상 발화가 구문적으로 길고 복잡할수록 $\mathrm{ND}$ 비율이 높아질 것 이라는 예상과는 반대되는 결과이다. 이러한 결과는 읽기 과제 에서 언어 처리의 부담이 감소했기 때문으로 생각해볼 수도 있 지만 그 상관의 정도가 낮았고 $(\mathrm{r}=-0.369)$ 그림설명 과제에서는 상관이 없는 것으로 나타났기 때문에 $(\mathrm{r}=-0.071)$ 이 결과의 해 석을 위해서는 추가적인 연구가 이루어져야 할 것으로 보인다.
본 연구의 의의는 말더듬 성인을 대상으로 다양한 과제 상황 에서 전체말속도, 조음속도, 발화 길이를 유창한 발화, $\mathrm{ND}$ 발 화, $\mathrm{AD}$ 발화로 나누어서 살펴보고 변인들 간의 상관관계를 살 펴보았다는 점이다. 본 연구를 통해 과제에 따라, 또한 산출된 발화의 비유창성 유무 및 범주에 따라 전체말속도와 조음속 도, 발화 길이의 특성이 다르다는 것을 확인할 수 있었다. 따라 서 연구 목적으로 말더듬 성인의 발화를 수집하여 언어 및 말 특성 분석 시 과제와 비유창성에 대한 고려가 반드시 필요할 것이다. 마찬가지로 임상에서 말더듬 성인의 평가 시, 과제에 따 른 전체말속도 특성이 다를 수 있기 때문에 다양한 과제가 필 요할 것이다. 반면, 조음속도는 과제와 발화 유형에 따른 차이 가 없었고, 발화 길이도 비유창한 발화와 유창한 발화 간에 차 이는 있었지만 $\mathrm{ND}$ 발화와 $\mathrm{AD}$ 발화 간에는 유의한 차이를 보이 지 않아서 진단의 변별 요소가 되기에는 한계가 있을 수 있다.

본 연구의 결과를 바탕으로 후속 연구에서는 첫째, $\mathrm{AD}$ 의 하 위 유형에 따른 발화의 전체말속도와 조음속도를 비교해볼 수 있을 것이다. 특히 $\mathrm{AD}$ 의 하위 유형 중 상대적으로 말더듬 중증 도가 심한 것으로 여겨지는 '비운율적 발성'에 포함된 비유창성 유형(연장, 막힘, 깨진 낱말)별 영향을 살펴볼 수 있을 것이다. 둘 째, 본 연구는 과제(읽기, 그림설명)에 따른 말속도와 발화 길이 의 차이를 추리통계방법을 사용하여 직접적으로 비교하지 않았 다. 발화 유형(유창한 발화, $\mathrm{ND}$ 발화, $\mathrm{AD}$ 발화) 간 비교를 위하여 각 발화 유형에 최소 2 개 이상의 발화가 포함되어야 하므로 연 구 참여자의 발화가 분석에서 제외된 경우가 발생하였기 때문이 다. 과제에 따른 직접 비교를 실시할 경우 더 많은 자료의 손실이 발생하게 되기 때문에 각 과제별로 특성을 파악하였다. 이는 반 구조화된 발화수집방법을 사용한 본 연구의 실험설계상의 한계 였던 것으로 생각할 수 있다. 하지만 이러한 발화수집방법은 인 위적인 발화수집 환경보다 말더듬 성인의 발화에서 나타난 말속 도 및 발화 길이의 특성을 잘 설명해줄 수 있었던 것으로 사료된 다. 구조화된 상황에서 수집한 발화는 특정한 기준에 따른 자 료만을 얻게 되기 때문에 그 결과를 실제 의사소통 상황에 적 용하기 어렵기 때문이다(Kim et al., 2006). 후속 연구에서는 다 양한 과제를 사용하여 말자료를 분석한 후 과제에 따른 차이를 직접적으로 비교할 수 있는 방법을 고려해볼 수 있을 것이다.

중심 단어 : 말더듬·발화 유형·전체말속도·조음속도. 평균형태소길이.

\section{Ethical Statement}

This study was approved by the Institutional Review Board of Chosun University (2-1041055-AB-N-01-2013-0005).

\section{Acknowledgments}

N/A 


\section{Declaration of Conflicting Interests}

There are no conflict interests.

\section{Funding}

This study was supported by research fund from Chosun University, 2016.

\section{Author Contributions}

All authors contributed equally to this work. H.C. and S.L. designed and performed experiments, analyzed data, and wrote the paper. Also, the authors discussed the results together and commented on the manuscript at each stage.

\section{ORCID iDs}

HeeCheong Chon

Soo Bok Lee

https://orcid.org/0000-0002-9715-7164

https://orcid.org/0000-0001-6942-4635

\section{REFERENCES}

Ahn, J. B., Shin, M. S., \& Kwon, D. H. (2002). The study of speech rate in normal-speaking adults and children. Speech Sciences, 9(4), 93-103.

Andrews, G., Howie, P. M., Dozsa, M., \& Guitar, B. E. (1982). Stuttering: Speech pattern characteristics under fluency-inducing conditions. Journal of Speech and Hearing Research, 25(2), 208-216.

Buhr, A. \& Zebrowski, P. (2009). Sentence position and syntactic complexity of stuttering in early childhood: A longitudinal study. Journal of Fluency Disorders, 34(3), 155-172

Boersma, P. \& Weenink, D. (2015, September 7). Praat: Doing Phonetics by Computer (Version 5.4.18) [computer program]. Retrieved from http:// www.fon.hum.uva.nl/praat/.

Cheon, S. (2008). Maximum phonation time and articulation diadochokinetic rate, speech rate of standardized passage in the healthy Korean elderly (Unpublished master's thesis). Yonsei University, Seoul.

Chon, H., Kraft, S. J., Zhang, J., Loucks, T., \& Ambrose, N. G. (2013). Individual variability in delayed auditory feedback effects on speech fluency and rate in normally fluent adults. Journal of Speech, Language, and Hearing Research, 56(2), 489-504.

Chon, H. \& Lee, S. B. (2016). Effects of stuttering severity on articulation rate in fluent and dysfluent utterances of preschool children who stutter. Phonetics and Speech Sciences, 8(3), 79-90.

Chon, H., Sawyer, J., \& Ambrose, N. G. (2012). Differences of articulation rate and utterance length in fluent and disfluent utterances of preschool children who stutter. Journal of Communication Disorders, 45(6), $455-467$.

Craig, C. (2013). Goldwave (Version 5.70) [computer software]. St. John's: Goldwave Inc.

de Andrade, C. R., Cervone, L. M., \& Sassi, F. C. (2003). Relationship between the stuttering severity index and speech rate. São Paulo Medical Journal, 121(2), 81-84.

Duchin, S. W. \& Mysak, E. D. (1987). Disfluency and rate characteristics of young adult, middle-aged, and older males. Journal of Communication Disorders, 20(3), 245-257.

Hall, K. D., Amir, O., \& Yairi, E. (1999). A longitudinal investigation of speaking rate in preschool children who stutter. Journal of Speech, Language, and Hearing Research, 42(6), 1367-1377.

Howell, P. \& Kadi-Hanifi, K. (1991). Comparison of prosodic properties between read and spontaneous speech material. Speech Communication, 10(2), 163-169.

Ingham, J. C. \& Riley, G. (1998). Guidelines for documentation of treatment efficacy for young children who stutter. Journal of Speech, Lan guage, and Hearing Research, 41(4), 753-770.

Kim, T. K., Chang, K. H., \& Lee, P. Y. (2006). Increase in speaking rate by 3-8-year-old Korean children. Speech Sciences, 13(3), 83-95.

Kim, Y. T. (1997). Basic study on utterance mean length in Korea 2-4 yearold children. Korean Journal of Communication Disorders, 2, 5-26.
Kleinow, J. \& Smith, A. (2000). Influences of length and syntactic complexity on the speech motor stability of the fluent speech of adults who stutter. Journal of Speech, Language, and Hearing Research, 43(2), 548559.

Kloth, S. A. M., Janssen, P., Kraaimaat, F. W., \& Brutten, G. J. (1995). Speechmotor and linguistic skills of young stutterers prior to onset. Journal of Fluency Disorders, 20(2), 157-170.

Ko, Y. M., Kim, D. Y., Choi, Y. L., \& Kim, H. H. (2010). Speech rate and pause characteristics in patients with Parkinson's disease. Phonetics and Speech Sciences, 2(4), 173-184.

Lee, S. B. \& Sim, H. S. (2015). A longitudinal study of utterance length in morphemes as a predictor of treatment outcome in early childhood stuttering. Communication Sciences and Disorders, 20(2), 189-201.

Logan, K. J. \& Conture, E. G. (1995). Length, grammatical complexity, and rate differences in stuttered and fluent conversational utterances of children who stutter. Journal of Fluency Disorders, 20(1), 35-61.

Malécot, A., Johnston, R., \& Kizziar, P. A. (1972). Syllabic rate and utterance length in French. Phonetica, 26(4), 235-251.

Manning, W. H. (2010). Clinical Decision Making in Fluency Disorders. (3rd ed.). Clifton Park, NY: Delmar Cengage Learning,

Manning, W. H. \& Shirkey, E. A. (1981). Fluency and the aging process. In Beasley, D. S. \& Davis, G. A. Aging, Communication Processes and Disorders. New York, NY: Grune \& Stratton.

McLaughlin, S. F. \& Cullinan, W. L. (1989). Disfluencies, utterance length, and linguistic complexity in nonstuttering children. Journal of Fluency Disorders, 14(1), 17-36.

Miller, J. L., Grosjean, F., \& Lomanto, C. (1984). Articulation rate and its variability in spontaneous speech: A reanalysis and some implications. Phonetica, 41(4), 215-225.

Navarro-Ruiz, M. I. \& Rallo-Fabra, L. (2001). Characteristics of mazes produced by SLI children. Clinical Linguistics and Phonetics, 15(1-2), 63-66

Park, J. W. \& Kwon, D. H. (2010). According to the severity of stuttering adults of speed rate characteristics comparison study. Journal of Special Education: Theory and Practice, 11(1), 129-146.

Rispoli, M. \& Hadley, P. (2001). The leading-edge: The significance of sentence disruptions in the development of grammar. Journal of Speech, Language, and Hearing Research, 44(5), 1131-1143.

Robb, M. P., Sargent, A., \& O’Beirne, G. A. (2009). Characteristics of disfluency clusters in adults who stutter. Logopedics, Phoniatrics, Vocology, 34(1), 36-42.

Sadagopan, N. \& Smith, A. (2008). Developmental changes in the effects of utterance length and complexity on speech movement variability. Journal of Speech, Language, and Hearing Research, 51(5), 1138-1151.

Shim, H. (2005). A study of disfluency characteristics and speech rates in normal Korean adults (Unpublished doctoral dissertation). Hallym University, Chuncheon.

Sim, H. S., Shin, M. J., \& Lee, E. J. (2010). Paradise Fluency Assessment-II. Seoul: Paradise Welfare Foundation.

Staróbole Juste, F. \& Furquim de Andrade, C. R. (2011). Speech disfluency types of fluent and stuttering individuals: Age effects. Folia Phoniatrica et Logopaedica, 63(2), 57-64.

Sturm, J. A. \& Seery, C. H. (2007). Speech and articulatory rates of schoolage children in conversation and narrative contexts. Language, Speech, and Hearing Services in Schools, 38(1), 47-59.

Tumanova, V., Zebrowski, P. M., Throneburg, R. N., \& Kulak Kayikci, M. E. (2011). Articulation rate and its relationship to disfluency type, duration, and temperament in preschool children who stutter. Journal of Communication Disorders, 44(1), 116-129.

Yairi, E. \& Ambrose, N. G. (2005). Early Childhood Stuttering for Clinicians by Clinicians. Austin, TX: Pro-Ed.

Yaruss, J. S. \& Conture, E. G. (1995). Mother and child speaking rates and utterance lengths in adjacent fluent utterances: Preliminary observations. Journal of Fluency Disorders, 20(3), 257-278.

Zackheim, C. T. \& Conture, E. G. (2003). Childhood stuttering and speech disfluencies in relation to children's mean length of utterance: A preliminary study. Journal of Fluency Disorders, 28(2), 115-142. 